\title{
Long-Term Comparative Evaluation of Acoustic Climate in Selected Schools Before and After Acoustic Treatment
}

\author{
Józef KOTUS, Maciej SZCZODRAK, \\ Andrzej CZYŻEWSKI, Bożena KOSTEK \\ Gdańsk University of Technology \\ Multimedia Systems Department \\ Narutowicza 11/12, 80-233 Gdańsk, Poland \\ e-mail: \{joseph, szczodry\}@sound.eti.pg.gda.pl \\ e-mail: \{andcz, bozenka\}@sound.eti.pg.gda.pl \\ (received May 4, 2010; accepted December 3, 2010)
}

\begin{abstract}
The results of long-term continuous noise measurements in two selected schools are presented in the paper. Noise characteristics were measured continuously there for approximately 16 months. Measurements started eight months prior to the acoustic treatment of the school corridors of both schools. An evaluation of the acoustic climates in both schools, before and after the acoustic treatment, was performed based on comparison of these two periods of continuous measurements. The autonomous noise monitoring stations, engineered at the Multimedia Systems Department of the Gdansk University of Technology were used for this purpose. Investigations of measured noise, especially its influence on hearing sense, assessed on ground of spectral analyses in critical bands, is discussed. Effects of occupational noise exposure, including the Temporary Threshold Shift simulation, are determined. The correlation of the above said measurement results with respective instantaneous noise levels is discussed, and concluding remarks are presented. Some additional indicators such as air pollution or video analysis aiming at the analysis of corridor occupancy are also measured. It should be remembered that excessive noise, or air pollution may be evidence of a dangerous event and may pose health risks.
\end{abstract}

Keywords: noise measurement, acoustic climate evaluation, acoustic treatment, noise dose.

\section{Introduction}

Research studies on acoustic climate in schools indicate that noise poses a serious threat for both pupils and teachers (FEARN, 1991, 1993; JAROSZEWSKI, Rogowski, 2000; Rogowski et al., 2001, Shield, Dockrell, 2003). Engel in his study (2010) indicated that noise pollution and its consequences were very often considered at Noise Control conferences. Gdańsk acousticians, together with 
their cooperating colleagues from abroad, many years ago warned against harmful effects of excessive noise- or music levels, and investigated particular threats, endangering the hearing sense of young people (KOWALCZUK, 1967; BUDZYŃSKI et al., 1992; Kostek et al., 1993). Rudno-Rudzińska and CzAjKowska (2010) point out in their study that an acoustic environment quality should be assessed for preschools and schools. They carried out such an investigation for 118 nursery schools located in Wrocław. A recent paper delivered information about noise and hearing measurements conducted in two primary schools (KOTUs et al., 2009). The measurements were done as a continuation of earlier screening hearing tests carried out by means of the "I can hear" system in numerous schools throughout the country (CZYŻEWski et al., 2006; CZYŻEWSki, SkARŻYŃSKI, 2007; KosteK, 2005; SKARŻYŃSKI et al., 2003). Earlier surveys revealed frequent occurrence of various hearing problems among pupils (JAROsZEWSKI, JAROsZEWsKA, 2000; JAROSZEWSKI et al., 1998; 1999). Results of these measurements show that the $A$-weighted maximum noise level during every break between lessons exceeded $100 \mathrm{~dB}$, and in addition, the averaged level over one minute often exceeded $90 \mathrm{~dB}$. Therefore the idea of an acoustic climate improvement has arisen. School authorities approved the concept of corridors acoustic adaptations in order to reduce noise. This task was completed by two companies Ecophon and MJ Audio Lab that volunteered their participation in this project (Ecophon, 2010; MJ Audio Lab, 2010).

Since December 2008 noise measurements have been performed by means of automatic noise measurements stations designed and assembled in the Multimedia System Department of the Gdańsk University of Technology (GUT) (CZYŻEWsKi et al., 2005a; 2005b; 2008).

These stations, installed in corridors of both schools, were operating during long lasting periods before and after accomplishment of the mentioned acoustic adaptations. The main purpose of the long lasting measurements is a comparative analysis of their results, permitting to evaluate the effectiveness of applied treatments. Moreover, the research action is conceived as a means for quantitative description of noise hazards at schools. In this study, the noise dose analysis was expanded by the assessment of the harmfulness of long noise exposure based on the psychoacoustic features of the human hearing system (KoTUs et al., 2008; Kotus, Kostek, 2008).

\section{Measurements}

\subsection{Localization}

Noise measurements were performed in the two selected primary schools in Warsaw, Poland. The noise monitoring stations were placed in corridors near classrooms. Outdoor noise was neglected (schools are located in quiet places). The data gathered were utilized to perform the noise dose analysis. This was done to determine the noise exposures in the above-mentioned schools. 


\subsection{Acoustic treatment of corridors}

The acoustic treatment in each of the two locations was performed separately, along with an individual design. The construction works took place during the 2010 winter holidays for school 1 and during the 2009 summer holidays for school 2. Both adaptations consisted in the placement of highly sound absorbing material suspended below the corridor ceiling, because placing the materials on the walls, then within reach of pupils, would be highly unpractical. In school 1128 panels measuring $1000 \times 500 \times 50 \mathrm{~mm}$ made of foam were mounted. At the request of the school authorities, the panels remained in their covers for easy cleaning. The view of the corridor after panel installation is depicted in Fig. 1. Sound absorption characteristics according to EN ISO 354 for this material are presented in Table 1.
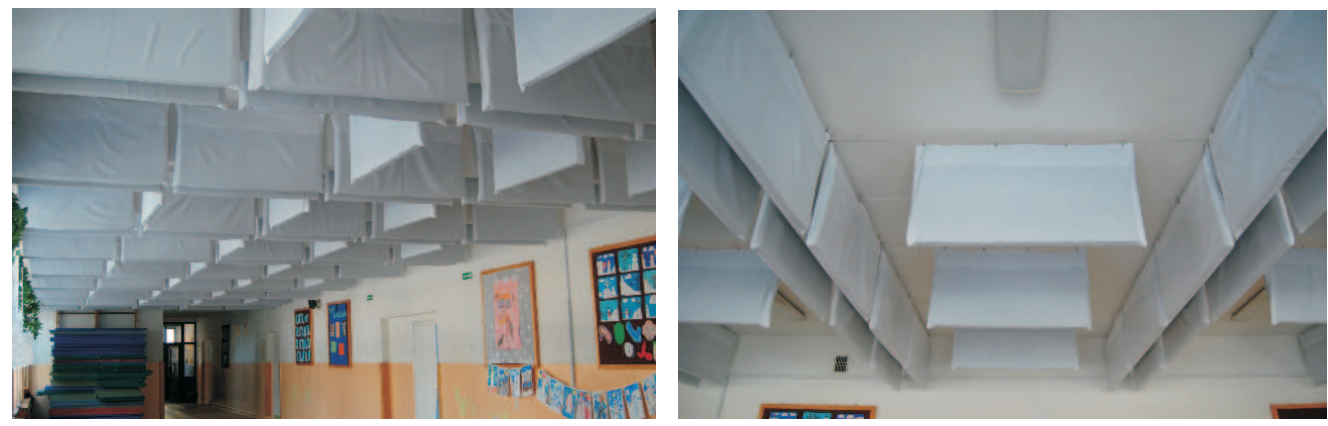

Fig. 1. School 1 corridor after acoustic adaptation.

In school 2, the utilized material is 'Ecophon Gedina A' $600 \times 600 \mathrm{~mm}$ tiles, thickness $15 \mathrm{~mm}$. The tiles are manufactured from high density (approx. $60 \mathrm{~kg} / \mathrm{m}^{3}$ ) glass wool. Tiles were mounted to a special grid and form a suspended ceiling. The gap between the base ceiling and the tiles is $35 \mathrm{~mm}$. Sound absorption characteristics according to EN ISO 354 for this material (without cover) are presented in Table 1. A picture from the monitoring station camera showing the construction of the ceiling is presented in Fig. 2. Values of sound absorp-
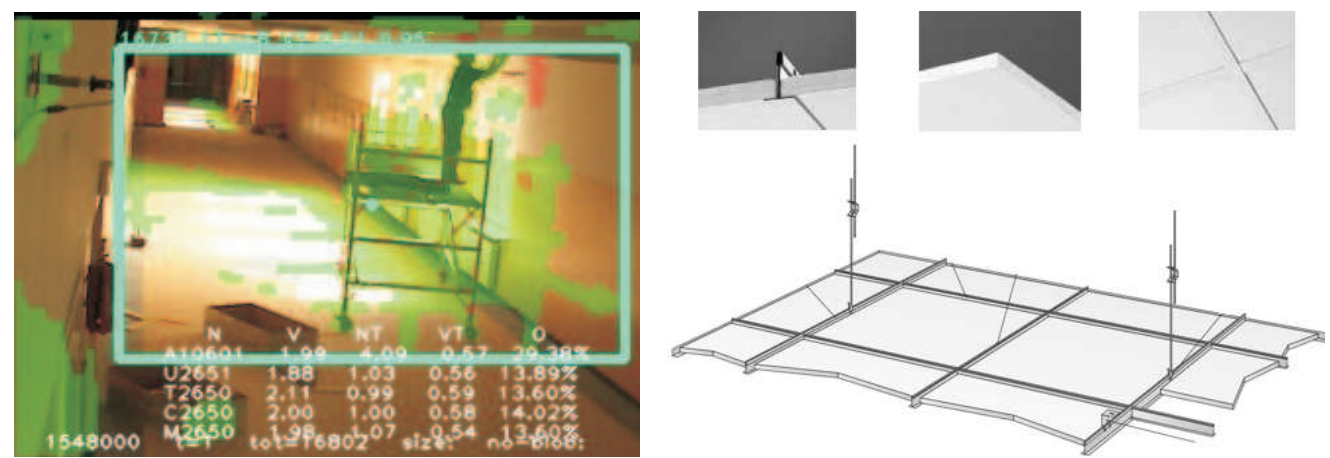

Fig. 2. School 2 corridor (left) and the material mounted (right) (Ecophon, 2010). 
tion coefficient for both materials are taken from the catalogues presented by the companies which realized the acoustic adaptation.

Table 1. Sound absorption coefficient $\left(\alpha_{p}\right)$ for materials used in schools 1 and 2 .

\begin{tabular}{|c|c|c|c|c|c|l|}
\hline$f[\mathrm{~Hz}]$ & 125 & 250 & 500 & 1000 & 2000 & 4000 \\
\hline$\alpha_{p, \text { school } 1}$ & 0.15 & 0.65 & 1.0 & 0.95 & 0.9 & 0.95 \\
\hline$\alpha_{p, \text { school } 2}$ & 0.1 & 0.35 & 0.8 & 1.0 & 1.0 & 0.9 \\
\hline
\end{tabular}

\subsection{Hardware}

A specialized system for continuous long-term measurement of sound level and other environmental parameters was utilized. The mentioned system preliminarily designed for the continuous monitoring of the acoustic climate of urban areas was developed and implemented by the Multimedia Systems Department (GUT). The assessment of environmental threats was performed based on the online data, acquired through a grid of engineered monitoring stations (SzCZODRAK et al., 2008). Each monitoring station is modularly designed to support various acquisition devices, i.e.: sound level meter, weather station, camera, air quality sensor. The block diagram of the station is presented in Fig. 3.

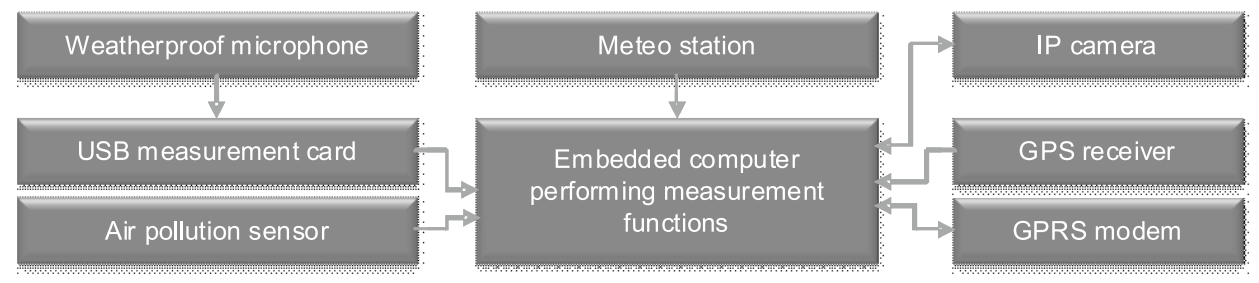

Fig. 3. Block diagram of the autonomous noise monitoring station.

Sound level meters, preinstalled in all of the active monitoring stations, are a class 1 product designed and built at the Multimedia Systems Department, GUT (Kotus et al., 1999). The remote sound level meter consists of a noise measuring microphone and a USB acquisition board. The device is capable of acquiring sound pressure levels with dynamics reaching to $100 \mathrm{~dB}$. The discussed meter is fully configurable in terms of acquisition time, applied correction curve (A, C) and sensitivity. A high resolution IP camera acquires the video signal for further analysis, such as road traffic volume and characteristics estimation (Czyżewski, Dalka, 2008). Due to the mobility, modular built and compact casing, this device may be used for monitoring acoustic climate in closed and opened spaces. Based on the open source software components and utilizing a central unit with low power consumption, the station discussed has low introduction and running costs. An optionally installed air quality sensor acquires information about the concentration of benzene, fumes and all other harmful airborne factors. 
A unique and a very important feature of the system is the elaborated concept of the psychoacoustic noise dosimeter (CZYŻEWski et al., 2007; KотUs et al., 2008; Kotus, Kostek, 2008). The construction of the dosimeter is based on a modified psychoacoustic model of hearing and on the research results of noise impact on hearing performed with the participation of volunteers that agreed to take part in these experiments. The primary function of a dosimeter is to estimate, in a real time, auditory effects which are caused by exposure to noise.

\subsection{Measured parameters}

During the long-term continuous complex acoustic climate evaluation in selected schools, the following parameters were taken into consideration (SzCZODRAK et al., 2008):

- noise parameters - time averaging equals one hour: $L_{A F \text { min }}, L_{A e q}, L_{A F \max }$, measured independently over octave and one-third octave band spectrum over each hour, cumulative distribution of the $L_{A S}$ instantaneous levels $\left(L_{A F \min }, L_{A F \max }\right.$, - the lowest and highest $A$-weighted sound levels for fast time weighting that occurred during the measurement), and $L_{A e q}-$ the $A$-weighted equivalent continuous noise level over a specified period of time that represents the same energy as the actual time varying noise signal (Polish Standard, 1994);

- noise parameters - time averaging equals one minute: $L_{A S \text { min }}, L_{A e q}, L_{A S \text { max }}$, $L_{A S S P L}, L_{C p k}, L_{T H}$ and TTS in critical bands;

- video analysis - time averaging equals one minute: number of objects in the frame and corridor occupancy indicator expressed in \%;

- air pollution indicator - averaged for one minute, the total value expressed in $\%$.

The noise monitoring station and other measuring sensors were installed $2.4 \mathrm{~m}$ above the floor, preventing accidental access to the equipment. This was to meet safety requirements for pupils. An example of the installation of the monitoring station is shown in Fig. 4. The autonomous noise monitoring stations were calibrated and periodically checked using the Bruel\&Kjaer calibrator, type 4231.

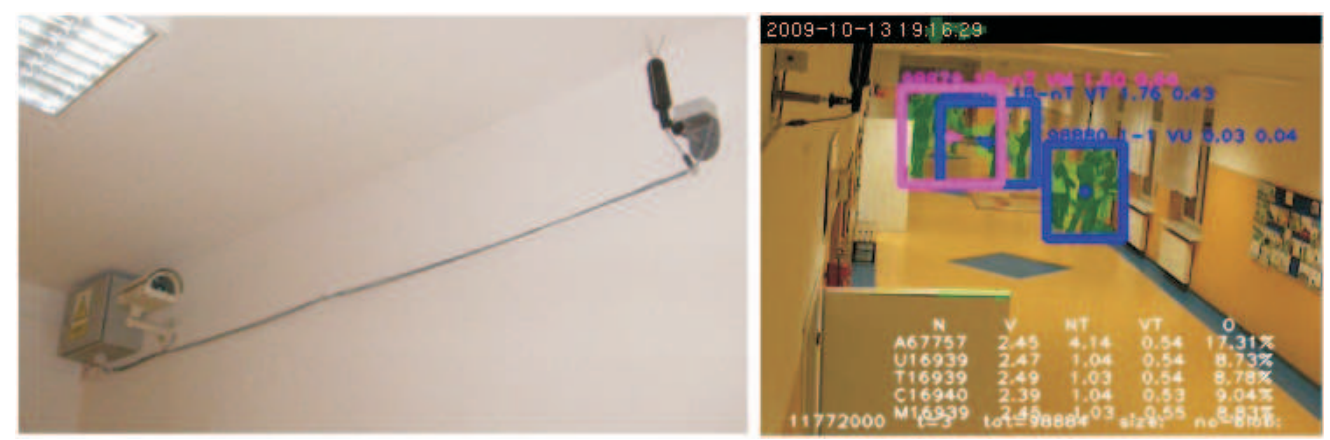

Fig. 4. One of the monitoring stations installed in a school (left), result of the motion analysis for the image acquired by the IP camera (right). Marked rectangles follow discovered "objects" in motion. 
Apart from acoustic parameters, additional factors such as pupils' activity and air pollution indicator are measured based on an extended functionality of the monitoring station and they are presented in Sec. 3.5.

\section{Results}

\subsection{Long-term continuous noise measurements}

Continuous measurements of the noise acoustic climate have been conducted in the schools discussed since December 2008. The analysis of outcomes of the measurements which have been made since January 2009 to April 2010 is presented in this paper. Four weeks have been excluded from measurements with regard to two winter holidays and similarly 8 weeks due to the summer holidays.

The first type of analysis was the estimation of the summary of the equivalent level in schools for all workdays (Monday - Friday). Values of the equivalent noise level for certain hours were achieved in this manner. Figs. 5 and 6 present outcomes for school 1 and for school 2, respectively. The dotted (upper) line denotes the $L_{A e q}$ level before and the lower one - after the acoustic treatment.

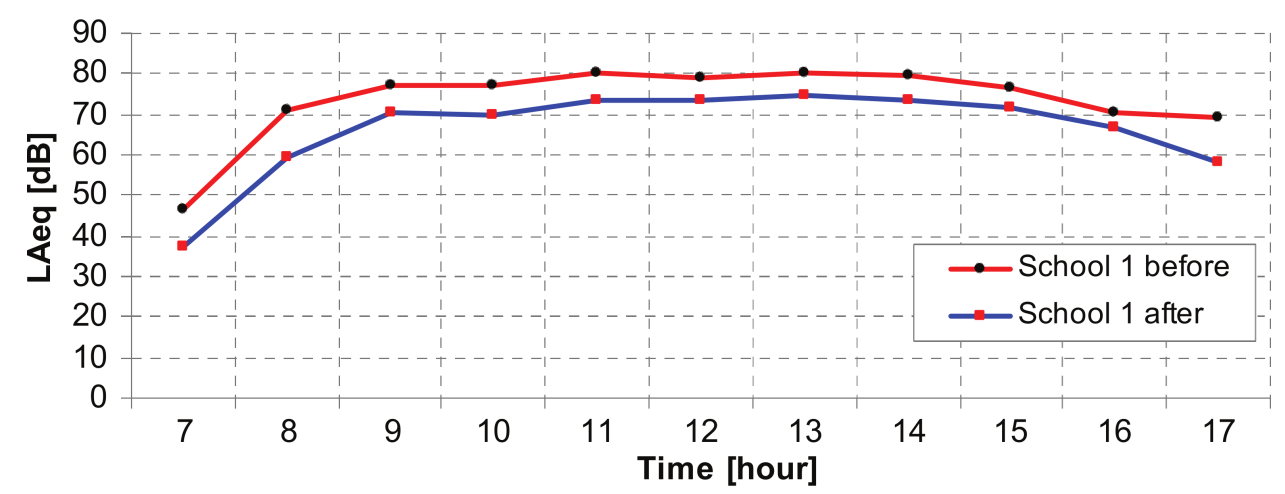

Fig. 5. A-weighted equivalent sound level for school 1, averaged over each working hour during all measurement periods, before and after the acoustic treatment.

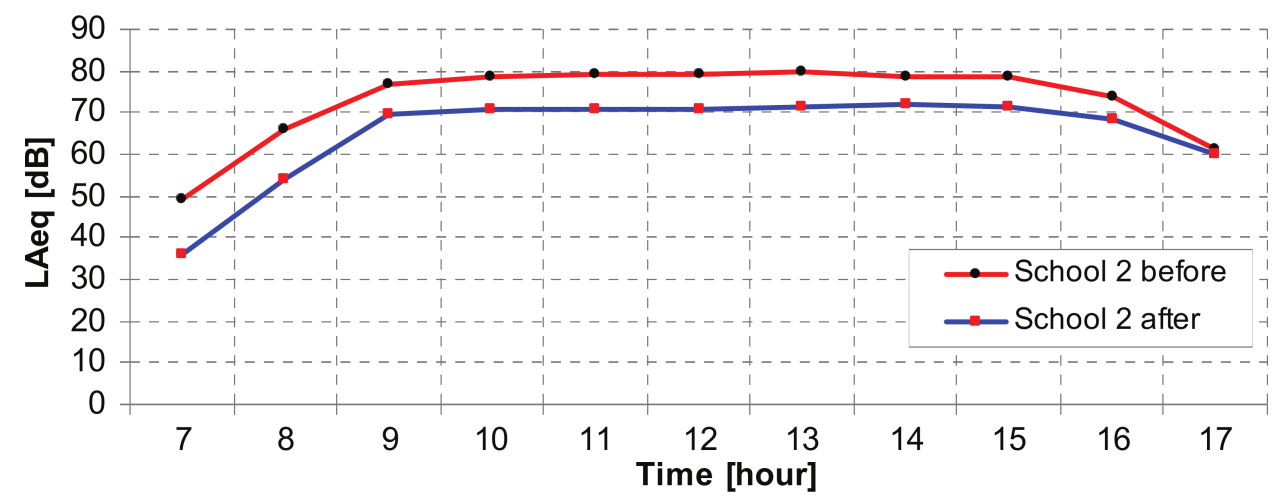

Fig. 6. A-weighted equivalent sound level for school 2, averaged over each working hour during all measurement periods, before and after the acoustic treatment. 
The final $A$-weighted equivalent noise level for a particular school, determined for hours between 8 and 16 and the entire measurement period before acoustic adaptation were equal to: $78.3 \mathrm{~dB}$ in school 1, and $78.4 \mathrm{~dB}$ in school 2. The equivalent level was used to determine the noise dose that occurred during the entire day (Criteria ... Occupational Noise exposure, 1998). It was equal to $21.4 \%$ daily noise dose for school 1 and $21.9 \%$ for school 2 . After acoustic adaptation in particular schools the obtained $L_{\text {Aeq }}$ indicator was equal to $72.4 \mathrm{~dB}$ for school 1 and $70.1 \mathrm{~dB}$ for school 2 . The daily noise doses were respectively equal to $5.5 \%$ and $3.7 \%$.

Table 2 presents the long term averaged $A$-weighted equivalent noise level over various periods of the day and before and after the acoustic treatment. The implementation of the acoustic treatment caused the decrease of the noise dose (the amount of acoustic energy) 4 times in school 1 and 6 times in school 2. However the number of measurement hours for school 1 after the acoustic treatment is much less than the number of hours before and thus the assessment is only approximate in this case.

Table 2. Noise level averaged over $24 \mathrm{~h}$ and the schools most busiest hours (8-16), $N$ denotes the number of measurement hours.

\begin{tabular}{|c|c|c|c|c|c|c|c|c|}
\hline \multirow{2}{*}{} & \multicolumn{4}{|c|}{ School 1 } & \multicolumn{4}{c|}{ School 2 } \\
\cline { 2 - 9 } & \multicolumn{2}{|c|}{$24 \mathrm{~h}$} & \multicolumn{2}{|c|}{$8.00-16.00$} & \multicolumn{2}{c|}{$24 \mathrm{~h}$} & \multicolumn{2}{c|}{$8.00-16.00$} \\
\cline { 2 - 9 } & $N$ & $L_{\text {Aeq }}$ & $N$ & $L_{\text {Aeq }}$ & $N$ & $L_{A e q}$ & $N$ & $L_{\text {Aeq }}$ \\
\hline Before & 4848 & 74.1 & 1616 & 78.3 & 2448 & 73.7 & 816 & 78.4 \\
\hline After & 1200 & 67.7 & 400 & 72.4 & 3600 & 66.1 & 1200 & 70.7 \\
\hline Difference & - & 6.3 & - & 5.9 & - & 7.5 & - & 7.6 \\
\hline
\end{tabular}

\subsection{Cumulative distribution evaluation}

A thorough analysis of cumulative distribution of the noise level was performed in order to present the type of noise which occurred in the schools discussed. The analysis was made on the basis of data containing typical classes during the week (Monday to Friday) between the hours of 8 and 16. The outcomes of this analysis for school 1 are presented in Fig. 7 and for school 2 in Fig. 8. The left-side curve denotes the $L_{A S}$ level before and the right-side after the acoustic treatment.

Each presented figure includes 2 charts. On the left side chart the $X$-axis presents the noise level for the $L_{A S}$ indicator and the $Y$-axis denotes the percentage of the time occurrence of a given noise level in the entire measurement time range. On the right side chart we can observe the difference in noise level before and after acoustic treatment.

Two maxima related to the individual acoustic climate character in both schools are visible. The first larger maximum is related to the relatively low noise 

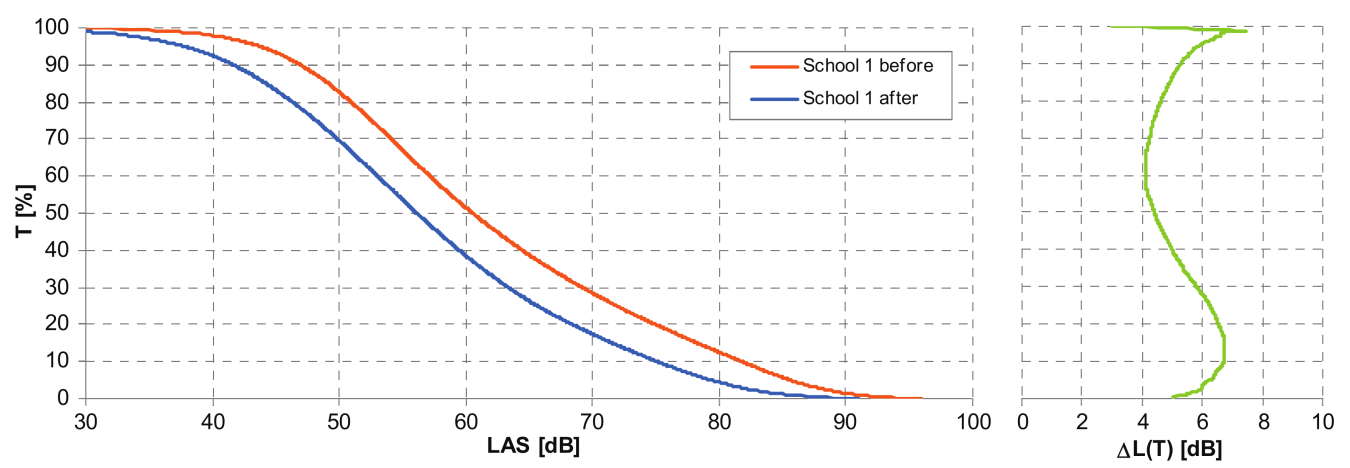

Fig. 7. The cumulative distribution for school 1 before and after the acoustic treatment.
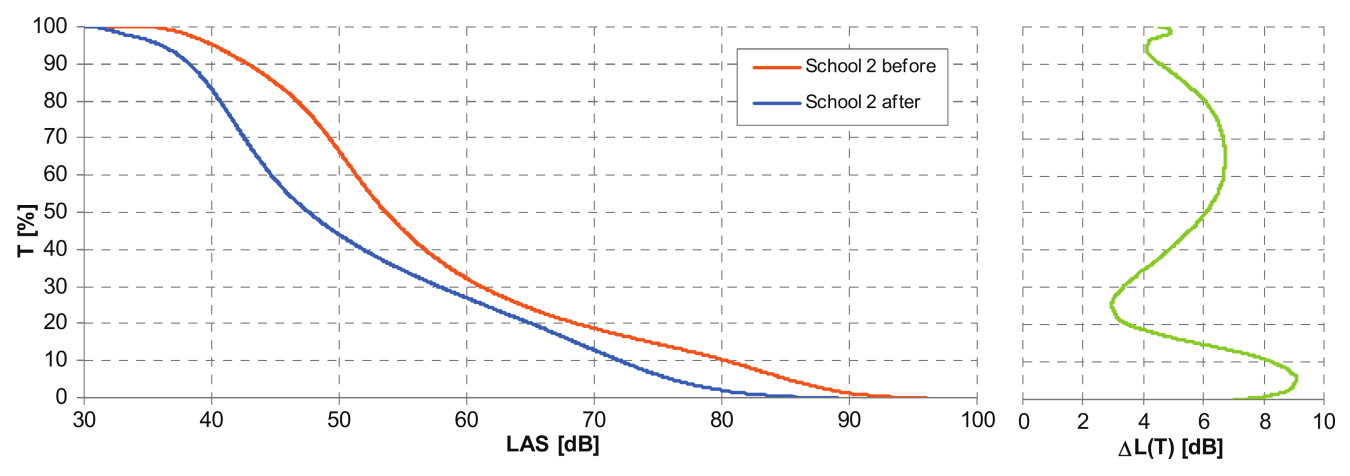

Fig. 8. The cumulative distribution for school 2 before and after the acoustic treatment.

level prevailing during classes. The second maximum, slightly lower, is related to the high noise level dominating during breaks.

A significant difference can be observed in the histograms for measurements before and after the acoustic treatment of corridors. For both schools the curve is shifted towards smaller noise levels and its shape does not change. The maximum change of $6.7 \mathrm{~dB}$ for school 1, and $9.1 \mathrm{~dB}$ for school 2 is apparent.

\subsection{Analysis in $1 / 3$ octave bands}

The detailed analysis of measured noise level was presented in this subsection. The measurements of working hours (8-16) are considered. The equivalent noise level in considered schools before and after acoustic treatment along with the noise level difference were presented in Figs. 9 and 10.

The highest noise reduction can be observed in range between $200 \mathrm{~Hz}$ and $5 \mathrm{kHz}$ in school 1 and between $250 \mathrm{~Hz}$ and $8 \mathrm{kHz}$ in school 2. Both bands cover the speech band $(300 \mathrm{~Hz}-3.4 \mathrm{kHz})$. Moreover, the outcomes are consistent with the material attenuation characteristics. 


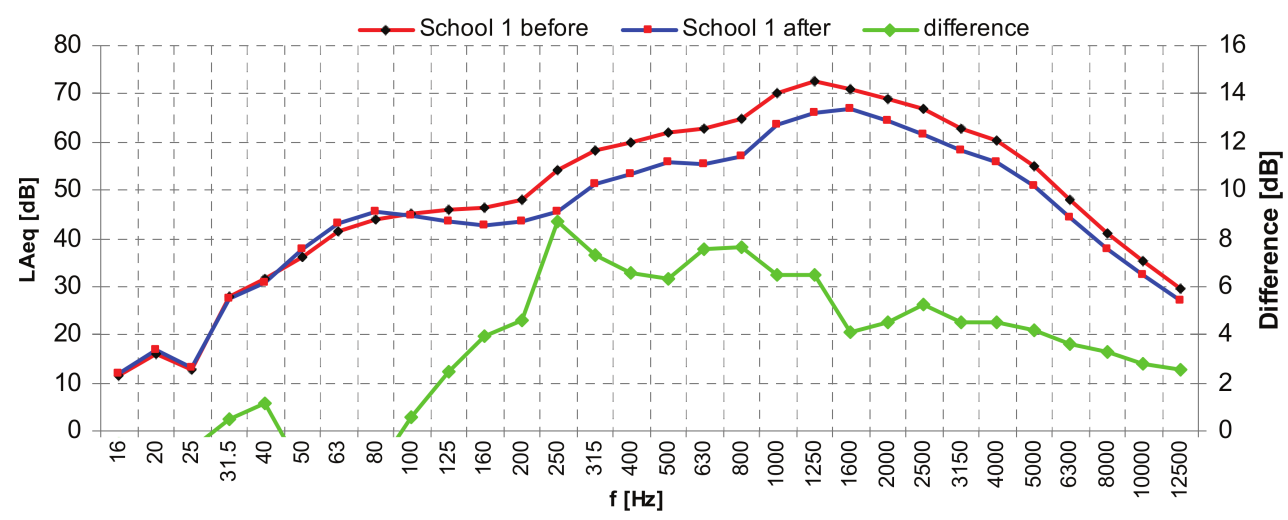

Fig. 9. The equivalent level of noise in $1 / 3$ octave bands.

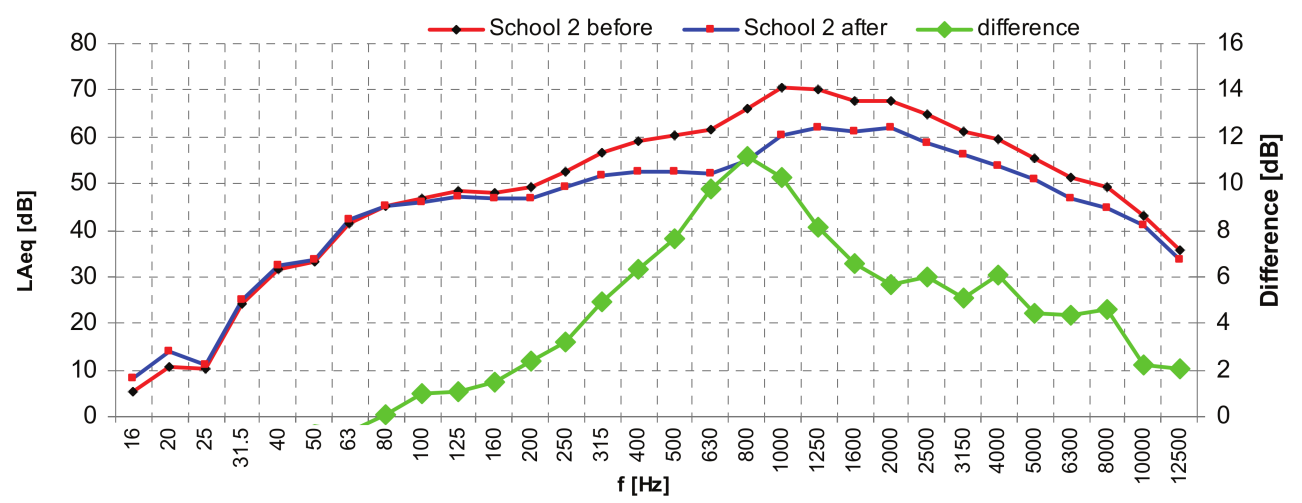

Fig. 10. The equivalent level of noise in $1 / 3$ octave bands.

\subsection{Noise exposure harmfulness assessment}

Before improvement of the sound attenuation in corridors, the noise levels in the schools discussed were very high, especially during breaks between lessons. The $A$-weighted equivalent sound level, averaged over a one minute period often exceeded $90 \mathrm{~dB}$. Based on the time character of the noise, the analysis of the noise impact on hearing introduced by the authors was performed (KoTUs, KOSTEK, 2006). It depends on the calculations of the instantaneous TTS (Temporary Threshold Shift) values in critical bands during the noise exposure (in real time). Figures 11 and 12 present the results of the equivalent noise level and the TTS analysis for both schools. The equivalent level $L_{A e q, 1 \text { min }}$ has been reduced and it does not exceed $82 \mathrm{~dB}$. The existence of the acoustic treatment of corridors also has a significant influence on decreasing the TTS effect by $3 \mathrm{~dB}$ during breaks.

It should strongly be emphasized that before the change of the acoustic characteristics of the school corridors, large TTS values were observed for frequency 


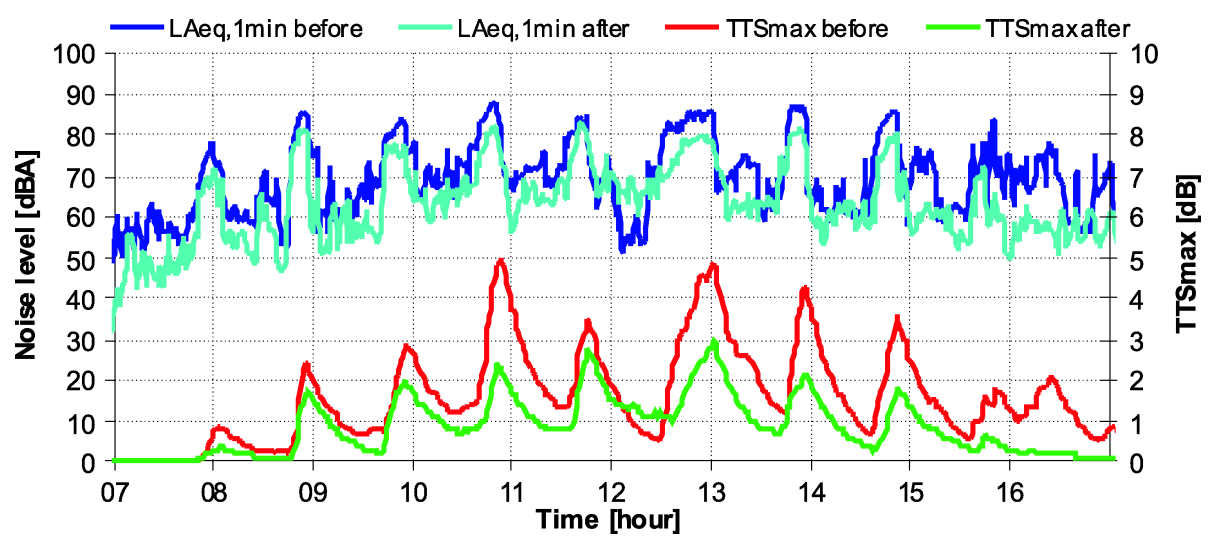

Fig. 11. Equivalent noise levels and the maximum instantaneous values of the TTS effect caused by noise for school 1 calculated for 10 hours, before and after the acoustic treatment.

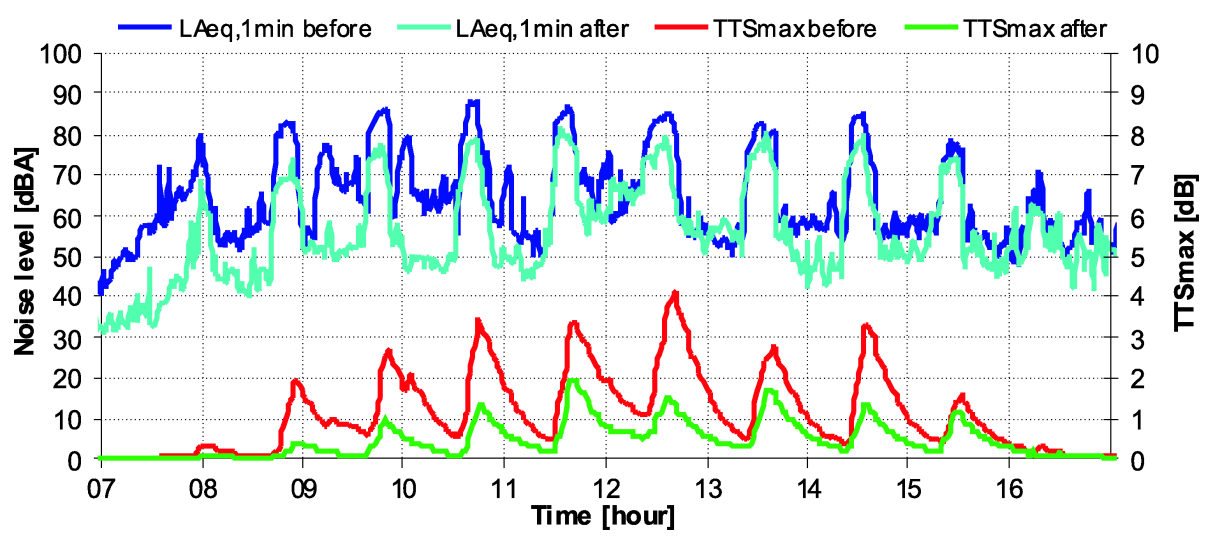

Fig. 12. Equivalent noise levels and the maximum instantaneous values of the TTS effect caused by noise calculated for school 2 for 10 hours, before and after the acoustic treatment.

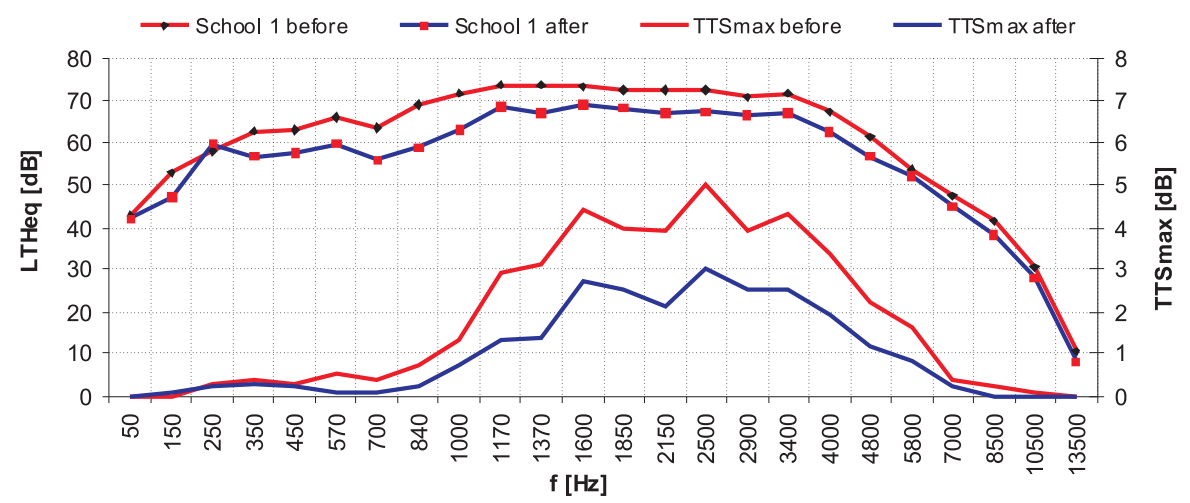

Fig. 13. The equivalent level of noise in the critical bands corrected according to Terhard's transfer function from outer to inner ear (KотUs et al., 2008) and the maximum values of the TTS effect evoked by noise during breaks between lessons, before and after the acoustic treatment. 
ranges essential for speech perception (from 1600 to $3400 \mathrm{~Hz}$ ). After the refitting of the corridors, the TTS in the mentioned band decreased nearly twice. The graphical illustration of this problem is provided in Figs. 13 and 14.

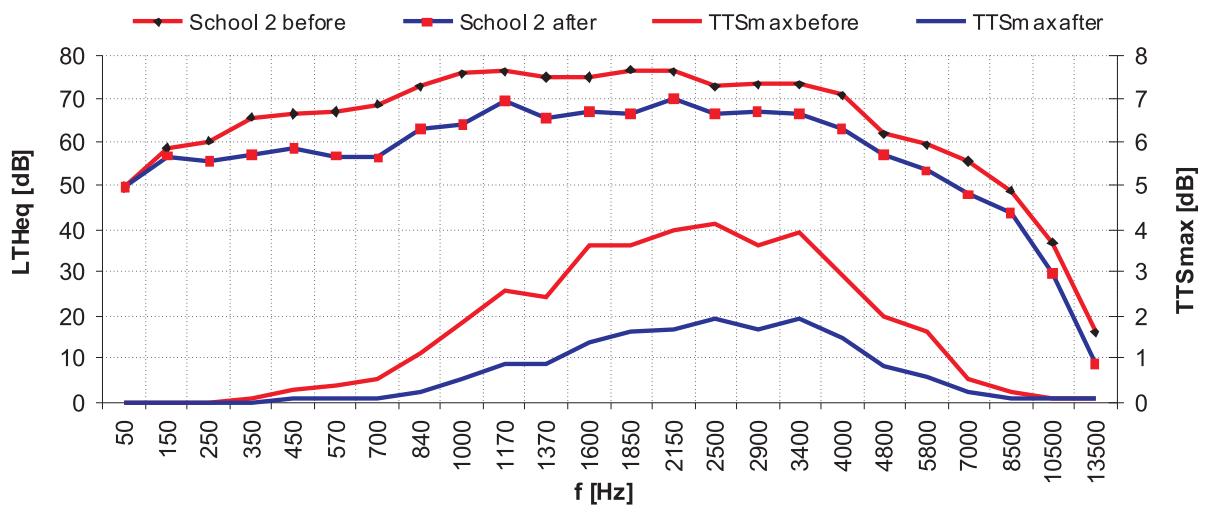

Fig. 14. The equivalent level of noise in the critical bands corrected according to Terhard's transfer function from outer to inner ear (Kotus et al., 2008) and the maximum values of the TTS effect evoked by noise during breaks between lessons, before and after the acoustic treatment.

\subsection{Additional parameters}

This subsection presents the results and discussion of extended measurements which were performed by the monitoring station in school 2. Two values are considered, namely the corridor occupancy coefficient and the air pollution coefficient. The first is evaluated employing the image processing algorithm which detects and counts moving objects in video sequence acquired by the IP camera. The second parameter value is acquired by the simple air pollution sensor. The charts presenting both parameters are depicted in Figs. 15 and 16.

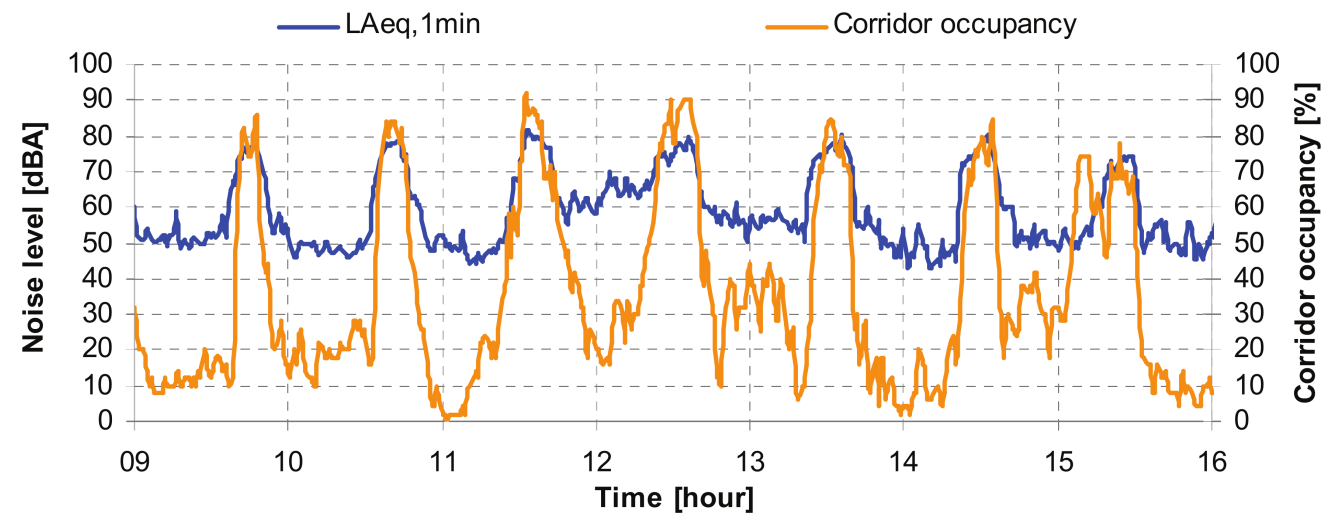

Fig. 15. The equivalent level of noise averaged for 1 minute along with the corridor occupancy coefficient. 


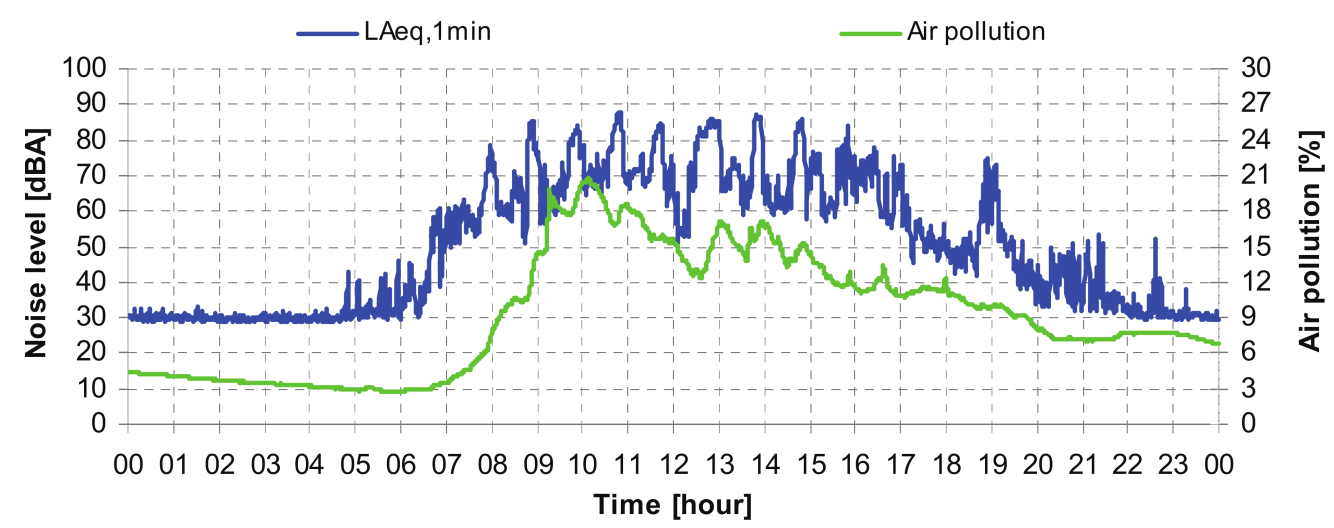

Fig. 16. The equivalent level of noise averaged for 1 minute along with the air pollution.

We can observe correlation between the corridor occupancy and the noise level. The maxima of occupancy coefficient arise during break periods and are congruent with measured sound level maxima. The air pollution in the corridor increases rapidly when the pupils come to school and decays slowly after the end of the classes.

\section{Conclusions}

The influence of the acoustic treatment of the schools corridors on the noise level was presented in this paper. A significant difference in sound field characteristics before and after the acoustic treatment was observed. The $A$-weighted equivalent sound level averaged over one minute does not exceed $82 \mathrm{~dB}$ in both schools. An improvement of acoustic comfort in the schools was achieved. Moreover, the negative influence of noise on hearing was decreased according to the results of the TTS parameter investigation which shows a $3 \mathrm{~dB}$ reduction during breaks. The positive effect has also been observed in the twice reduction of the TTS in a frequency range from 1600 to $3400 \mathrm{~Hz}$. After the acoustic treatment the dominant noise level observed during the breaks between lessons for all workdays between 8.00 and 16.00 decreased to $70-75 \mathrm{~dB}$ from the previously observed $83 \mathrm{~dB}$ (for schools 2 and 1). The amount of acoustical energy was diminished four times in school 1 and six times in school 2.

Such type of noise control method should always be considered as one of the important means of noise prevention.

\section{Acknowledgment}

Research is partially subsidized by the Polish Ministry of Science and Higher Education within Grant No. R00 O0005/3.

A special thanks to Ecophon and MJ Audio Lab for the acoustic treatment of corridors in the noise-abatement program for schools. 


\section{References}

1. Budzyński G., Whitehead G., Roland-Mieszkowski M., Papanikolaou G. (1992), Investigation of the loud-music-exposure hearing loss, 92nd Audio Eng. Soc. Convention, Vienna, Austria, Preprint 3312, 27 March.

2. Criteria for a recommended standard. Occupational Noise Exposure (1998), U.S. Department of Health and Human Services, June 1998.

3. Czyżewski A., Kotus J., Kulesza M. (2005a), Project and development of the automatic station for environmental noise monitoring [in Polish], [in:] Proceedings of ISSET 2005, pp. 53-60, Kraków, 23-25 June.

4. Czyżewski A., Kostek B., Skarżyński H. (2005b), Intelligent System for Environmental Noise Monitoring, [in:] Advances in Soft Computing, pp. 397-410, Springer Verlag.

5. Czyżewski A., Kostek B., Skarżyński H. (2006), IT Applications for the Remote Testing of Hearing, pp. 225-247, Springer Verlag.

6. Czyżewski A., Kotus J., Kostek B. (2007), Determining the noise impact on hearing using psychoacoustical noise dosimeter, Archives of Acoustics, 32, 2, 215-229.

7. Czyżewski A., Skarżyński H. (2007), Multimedia Applications for the Hearing Impaired, Archives of Acoustics, 32, 2, 491-504.

8. Czyżewski A., Kostek B., Kotus J. (2008), Multimedia Interactive Services in Intelligent Environments; Multimedia Services Applied to Noise and Hearing Monitoring and Measuring, chapter, pp. 275-295, Springer Verlag.

9. Czyżewski A., Dalka P. (2008), Moving Object Detection and Tracking for the Purpose of Multimodal Surveillance System in Urban Areas, New Directions in Intelligent Interactive Multimedia, series: Studies in Computational Intelligence, 142, 75-84.

10. Ecophon - www.ecophon.pl, access 30.04.2010.

11. Engel Z. (2010), From the history of the Noise Control Conference, Archives of Acoustics, 35, 2, 133-142.

12. FEARN R.W. (1991), Serial audiometry in young subjects aged 11-25 years exposed to amplified music, Journal of Sound and Vibration, 150, 350-355.

13. Fearn R.W. (1993), Hearing loss in musicians, Journal of Sound and Vibration, 163, $372-378$.

14. Jaroszewski A., Rogowski P., Rakowski A. (2000), Sound pressure levels in emission of percussion instruments during training sessions, Archives of Acoustics, 25, 3, 283-289.

15. Jaroszewski A., Jaroszewska A. (2000), Impulsiveness of discotheque exposures, Archives of Acoustics, 25, 3, 275-281.

16. Jaroszewski A., Fidecki T., Rogowski P. (1998), Hearing damage from exposure to music, Archives of Acoustics, 23, 1, 3-24.

17. Jaroszewski A., Fidecki T., Rogowski P. (1999), Exposures and hearing thresholds in music students due to training sessions, Archives of Acoustics, 24, 2, 111-118.

18. Kostek B., Czyżewski A., Budzyński G., Sankiewicz M., Whitehead G., RolandMieszkowski M. (1993), Sound exposure in the entertainment business, Canadian Acoustics, Proc. issue, 21, 3, 11. 
19. Kostek B. (2005), Perception-Based Data Processing in Acoustics. Applications to Music Information Retrieval and Psychophysiology of Hearing, Springer Verlag, Series on Cognitive Technologies, Berlin, Heidelberg, New York.

20. Kotus J., Kostek B. (2006), Investigation of noise threats and their impact on hearing in selected schools - a pilot study, Archives of Acoustics, 31, 4 (Supp.), 417-424.

21. Kotus J., Czyżewski A., Kostek B. (2008), Evaluation of Excessive Noise Effects on Hearing Employing Psychoacoustic Dosimetry, Noise Control Engineering Journal, 56, 6, $497-510$.

22. Koтus J., Kosteк B. (2008), The assessment of the Noise-Induced harmful effects based on the properties of human hearing system, Archives of Acoustics, 33, 4, 435-440.

23. Kotus J., Szczodrak M., Czyżewski A., Kostek B., Skarżyński H. (2009), Longterm continuous complex acoustical climate evaluation in selected schools, EuroNoise 2009, 26-28 October, Edinburgh, Scotland.

24. Kowalczuk H. (1967), Big-beat music and hearing loss [in Polish], Otolaryngologia Polska, 21, 2, 161-167.

25. MJ Audio Lab - www.mjaudiolab.pl, access 30.04.2010.

26. Polish Standard PN-N-01307 (1994), Permissible sound level values in work-places and general requirements concerning taking measurements [in Polish].

27. Rogowski P., Rościszewska T., Jaroszewski A. (2001), Sound reproduction levels in portable players used by pupils in Warsaw secondary schools, Archives of Acoustics, 26, 1 , $3-10$.

28. Rudno-Rudzińska B., Czajkowska K. (2010), Analysis of acoustic environment on premises of nursery schools in Wrockaw, Archives of Acoustics, 35, 2, 245-252.

29. Shield B.M., Dockrell J.E. (2003), The effects of noise on children at school: a review, Journal of Building Acoustics, 10, 2, 97-106.

30. Skarzynski H., Czyzewski A., Senderski A., Kochanek K. (2003), "I can hear": a system for universal hearing screening in school age children. Organization and first results, International Congress Series, 1240, 325-327.

31. Szczodrak M., Czyżewski A., Kotus J. (2008), Investigation of the road noise source employing an automatic noise monitoring station, Archives of Acoustics, 33, 4, 77-83. 